\title{
Effect of different sterilization methods on sensory quality and volatile flavor of crab meat sauce
}

\author{
Yajun $\mathrm{Zhu}^{1+}$, Haoran $\mathrm{Wu}^{1+}$, Futian Wang ${ }^{1}$, Shaotong Jiang ${ }^{1,2,3}$, Lin Lin ${ }^{1,2,3 *}$, Jianfeng Lu ${ }^{1,2,3 *}$ \\ ${ }^{1}$ School of Food and Biological Engineering, Hefei University of Technology, Hefei, China; ${ }^{2}$ Engineering Research Center \\ of Bio-process, Ministry of Education, Hefei University of Technology, Hefei, China; ${ }^{3}$ Key Laboratory for Agricultural \\ Products Processing of Anhui Province, Hefei University of Technology, Hefei, China
}

${ }^{+}$The authors contributed equally to this work.

*Corresponding authors: Lin Lin and Jianfeng Lu, School of Food Science and Engineering, Hefei University of Technology, 193 Tunxi Road, Hefei 230009, Anhui, China. Emails: lujf@sibs.ac.cn and linlin@hfut.edu.cn

Submitted: 23 February 2021; Accepted: 29 April 2021; Published: 5 July 2021

(C) 2021 Codon Publications

OPEN ACCESS CC) ORIGINAL ARTICLE

\begin{abstract}
The effects of pasteurization (PS), microwave sterilization (MS), ultrasonic sterilization (US), and high temperature sterilization (HTS) on the sensory quality and volatile flavor of canned flavor crab meat sauce (FCMS) were studied. Results showed that after PS, MS, US, and HTS treatment, the total viable count decreased to 28, 26, 58, and 18 colony forming unit (CFU) /g, respectively, and no coliform group was detected. PS and MS had no significant effect on the texture of FCMS $(P>0.05)$, but US and HTS reduced hardness and viscosity of FCMS. MS and HTS significantly reduced the $\mathrm{L}^{*}, \mathrm{a}^{*}$, and $\mathrm{b}^{*}$ values of FCMS $(P<0.05)$, while PS and US groups maintained the original brightness and red value. MS and HTS obviously reduced the sensory score of FCMS, while PS and US groups maintained the original sensory score. The evaluation of FCMS volatile flavor indicated that the contents of total esters in MS and HTS groups and total alcohols in the US group decreased. However, PS not only maintained the original total amount of esters in FCMS but also increased the content of alcohols, aldehydes, and ketones. Therefore, PS could be more feasible than other methods for the sterilization of FCMS.
\end{abstract}

Keywords: Crab meat sauce; sensory quality; volatile flavor; sterilization methods

\section{Introduction}

Chinese sauce, originating over 2500 years ago (Gao et al., 2010), is an indispensable fermented condiment similar to Korean doenjang. The annual production of soybean sauce in China is more than 5 million tons, accounting for over $55 \%$ of the world production (Wanakhachornkrai and Lertsiri, 2003). Traditional Chinese sauce includes fermented soybean sauce and broad bean sauce. However, with the improvement in the standard of living, the simple taste and flavor of traditional Chinese sauce were unable to meet people's needs. Therefore, many kinds of Chinese sauces combined with meat cubes have appeared on the market as commercial ready-to-eat products in recent years, in China (Gao et al., 2015). These ready-to-eat sauces not only enrich the flavor of traditional Chinese sauce but can also control the spoilage of meat cubes (Kargiotou et al., 2011).

Chinese mitten crab (Eriocheir sinensis) is an important freshwater aquaculture economic crab, which is widely distributed in coastal areas, rivers, and lakes in China (Cheng et al., 2008; Wu et al., 2019a). Crab meat is a high-protein and low-fat food, which is delicious, popular among consumers, and has high nutritional value (Chen and Zhang, 2007; Gu et al., 2013; Wang et al., 2016, 2018). However, due to the limitations such as growing season and life expectancy, it cannot be supplied to the market for a long time (Wu et al., 2019b). In addition, the crab meat has high moisture content and is prone to spoilage 
(Wu et al., 2020). Therefore, crab meat is added to the traditional soybean sauce to make a flavor crab meat sauce (FCMS), which adds the delicious taste of crab meat to the traditional Chinese sauce and also provides a new way for the development and utilization of crab meat.

In the production process, the raw crab meat, processing environment, equipment, and personnel all may cause the FCMS to be contaminated by microorganisms, and the sterilization process is the key to control the microbial content of the final product ( $\mathrm{Bu}$ et al., 2014; Ye et al., 2020). In order to ensure that the FCMS meets the microbiological standards during storage, transportation, and sales, we initially employed a high-temperature method $\left(121^{\circ} \mathrm{C}, 20 \mathrm{~min}\right)$ for sterilization. However, long-term high-temperature treatment may cause problems such as poor taste and darkening. Therefore, it is necessary to find an optimum sterilization process for FCMS that ensures the quality of the product. As a newly developed ready-to-eat flavor sauce, there have been few reports on the sterilization process of FCMS.

In order to investigate the effects of different sterilization methods on the sensory quality and volatile flavor of FCMS, we studied the effects of high-temperature sterilization (HTS), pasteurization (PS), microwave sterilization (MS), and ultrasonic sterilization (US) on the microorganisms, texture, color, sensory score, and volatile flavor of FCMS. Our research can be used as a reference in the search of the optimum sterilization method for FCMS.

\section{Materials and Methods}

\section{Raw materials}

Frozen crab meat was bought from Fuen Food Technology Co., Ltd. (Maanshan, Anhui, China) and stored in a freezer at $-18^{\circ} \mathrm{C}$ before use. Soybean sauce, white sugar, millet pepper, vegetable oil, scallion, ginger, garlic, white sesame, and alcohol were purchased from the local carrefour supermarket (hefei, Anhui, China) and were of food grade.

\section{Preparation of FCMS}

To prepare samples of the FCMS, frozen crab meat was thawed overnight at $4^{\circ} \mathrm{C}$ and then fried at $220^{\circ} \mathrm{C}$ for $5 \mathrm{~min}$. Fresh scallion, ginger, garlic, and millet pepper were washed and cut into small cubes. The scallion, ginger, and garlic were fried in the vegetable oil at a temperature of $200^{\circ} \mathrm{C}$ until golden brown, and then removed. Millet pepper, crab meat, sugar, and white sesame were added to the boiled soybean sauce, and the mixture was boiled with constant stirring for $10 \mathrm{~min}$. Lastly, a small amount of cooking wine was added to the soybean sauce, followed by 1 more minute of cooking. The cooked paste was hot-filled into sterilized glass bottles and divided into five groups. The control group (CP) FCMS did not undergo any treatment. The PS group was heated in a $95^{\circ} \mathrm{C}$ water bath for $30 \mathrm{~min}$, the MS group was treated in a microwave oven (NJLO7-3, Nanjing Jiequan Microwave Development Co., Ltd., China) at $400 \mathrm{~W}$ for $4 \mathrm{~min}$, the US group was processed for $10 \mathrm{~min}$ in an ultrasonic instrument (120 W (80 KHz), KQ-300VDE, Kunshan Ultrasonic Instruments Co., Ltd., China), and the HTS group was processed in an autoclave (LDZX-30KBS, Shanghai ShenAn Medical Instrument Factory) at $121^{\circ} \mathrm{C}$ for $15 \mathrm{~min}$.

\section{Microbiological analysis}

The total viable counts were determined according to the Chinese National Standards: GB 4789.2-2016 (Standards Press of China, 2016). One gram of sample was accurately weighed and blended using $9 \mathrm{~mL}$ of sterile saline solution (0.9\%). Each sample was serially diluted using sterile saline solution. The total viable counts were measured. The media used for counting total microorganisms was plate count agar (PCA) (Beijing Aoboxing Biotechnology Co., Ltd., Beijing, China). Each diluent $(1 \mathrm{~mL})$ was spread on the PCA plate and the agar plates were incubated at $37^{\circ} \mathrm{C}$ for $24 \mathrm{~h}$. Microbial counts were calculated and expressed as $\mathrm{Log} \mathrm{CFU} / \mathrm{mL}$. The coliform group test was conducted according to the Chinese National Standards: GB 4789.32010 (Standards Press of China, 2010).

\section{Texture analysis}

The hardness and viscosity of FCMS were measured at $25^{\circ} \mathrm{C}$ (room temperature) using a TA-XT plus texture analyzer (Stable Micro System, UK) equipped with $\mathrm{P} / 0.05$ cylindrical probe. Ten grams of FCMS was placed in a beaker, and the probe was inserted into the sample at a speed of $10 \mathrm{~mm} / \mathrm{s}$. The maximum penetration depth was $1 \mathrm{~cm}$. Each sample was measured three times.

\section{Color analysis}

Colors of control group (CP), PS, MS, US, and HTS were measured using a colorimeter (SC-100; Beijing Kangguang Optical Instrument Co. Ltd., China). Five grams of FCMS was accurately weighed and spread evenly on the bottom of a glass test dish, which was then placed on the base of the instrument. $\Delta E$ was calculated using the Equation (1):

$$
\Delta \mathrm{E}=\sqrt{\left(\mathrm{L}_{0}^{*}-\mathrm{L}^{*}\right)^{2}+\left(\mathrm{a}_{0}^{*}-\mathrm{a}^{*}\right)^{2}+\left(\mathrm{b}_{0}^{*}-\mathrm{b}^{*}\right)^{2}}
$$


where $L^{*}$ denotes the lightness of FCMS after sterilization, $a^{*}$ denotes redness/greenness of FCMS after sterilization, $b$ * denotes yellowness/blueness of FCMS after sterilization, $L_{0}^{*}$ denotes lightness of FCMS before sterilization, $a_{0}^{*}$ denotes redness/greenness of FCMS before sterilization, and $b_{0}^{*}$ denotes yellowness/blueness of FCMS before sterilization.

\section{Volatile compounds' analysis}

The extraction of volatile compounds was performed using headspace solid phase microextraction (HS-SPME) (Dong et al., 2019). Five grams of FCMS was placed in a $20 \mathrm{~mL}$ headspace vial and sealed with polytetrafluorethylenesilicone septa. The sample was incubated at $55^{\circ} \mathrm{C}$ for $5 \mathrm{~min}$ and the volatile compounds were then sampled with a 30 $\mu \mathrm{m}$ CAR/PDMS fiber (Stable Flex, Sigma Aldrich, St. Louis, MO, USA) for $40 \mathrm{~min}$. The determination of volatile compounds was carried out using GC/MS (5975C-7890A, Agilent, USA) equipped with a DB-5MS capillary column $(60 \mathrm{~m} \times 0.25 \mathrm{~mm}, 0.25 \mu \mathrm{m}$, Agilent Inc., USA). Desorption of the volatile compounds absorbed by the fiber was conducted by inserting the fiber into an injection port at $250^{\circ} \mathrm{C}$ for $5 \mathrm{~min}$. The injector and ion source temperatures were set at $250^{\circ} \mathrm{C}$ and $230^{\circ} \mathrm{C}$ respectively, and MS was scanned at $70 \mathrm{eV}$ over 35-550 a.m.u. The analysis was performed in the splitless mode. The flow rate of the helium on the DB-5MS capillary column was $1 \mathrm{~mL} / \mathrm{min}$. The following temperature program was used for the SPME procedure: (1) $40^{\circ} \mathrm{C}$ for $1 \mathrm{~min}$, (2) raised by $60^{\circ} \mathrm{C}$ at the ramp rate of $2.5^{\circ} \mathrm{C} / \mathrm{min}$ (held for $2 \mathrm{~min}$ ), (3) $250^{\circ} \mathrm{C}$ at $8^{\circ} \mathrm{C} / \mathrm{min}$ (maintained for $6 \mathrm{~min}$ ). Identification of the volatile compounds detected by Gas Chromatography-Mass Spectrometer (GC-MS) analysis was performed by comparing them with the reference mass spectra of the MS library of NIST 11 and Wiley 7.0 (more than $80 \%$ of similarity).

\section{Sensory analysis}

Sensory scores of FCMS were evaluated according to GB 24399-2009 (Standards Press of China, 2009) with slight improvements. Seven food engineering graduate students with sensory evaluation experience were invited to form an assessment team to conduct sensory evaluation based on the eight aspects: sweetness, umami, color, posture, ester, miso, taste coordination, and saltiness of FCMS. The highest score was 10, and the increase in score was directly proportional to the quality of FCMS.

\section{Statistical analysis}

The statistical analysis was performed using Statistical Package for Social Sciences (SPSS 17.0, IBM, SPSS Inc.,
Chicago, IL). One-way analysis of variance was applied to the data analysis and the differences were considered statistically significant when $P<0.05$. The results are expressed as mean values \pm standard deviation (SD).

\section{Results and Discussion}

\section{Microbiological analysis}

The effect of different sterilization methods on the sterilization effect of FCMS is shown in Table 1. Before sterilization, the total viable counts of FCMS was $2124 \mathrm{CFU} / \mathrm{g}$, and after PS, MS, US, and HTS, the total viable counts of FCMS decreased to $28,26,58$, and $18 \mathrm{CFU} / \mathrm{g}$, respectively, and no coliform group was detected in all samples, which complies with the GB 10612-2011 (Standards Press of China, 2011) requirements for the total viable counts of soy complex sauce and the limit of coliform group.

The quantity of microorganism is an important index to describe the degree of freshness of food, and excessive microbial content in food greatly reduces its shelf-life (Chen et al., 2019). Therefore, sterilization is a key process to control the quality of ready-to-eat products. In this study, four sterilization methods (PS, MS, US, and HTS) were used to sterilize FCMS. The results showed that the sterilization rates of the four sterilization methods reached $98.68 \%, 98.78 \%, 97.27 \%$, and $99.15 \%$, respectively, indicating that all four sterilization methods were effective for sterilizing FCMS.

\section{Texture analysis}

The effect of four sterilization methods on the hardness and viscosity of FCMS is shown in Figure 1. Among them, the hardness and viscosity of FCMS were significantly reduced after HTS, while there was no significant

Table 1. Effect of different sterilization methods on the total viable counts of FCMS.

\begin{tabular}{lcc} 
Sterilization methods & $\begin{array}{c}\text { Total viable } \\
\text { colonies (CFU/g) }\end{array}$ & $\begin{array}{c}\text { Sterilization } \\
\text { rate (\%) }\end{array}$ \\
\hline CP & $2124 \pm 98^{\mathrm{a}}$ & - \\
$\mathrm{PS}\left(95^{\circ} \mathrm{C}\right.$ water bath/30 min) & $28 \pm 5^{\mathrm{c}}$ & $98.68^{\mathrm{b}}$ \\
$\mathrm{MS}(400 \mathrm{~W} / 4 \mathrm{~min})$ & $26 \pm 4^{\mathrm{c}}$ & $98.78^{\mathrm{b}}$ \\
US (120 W/80 KHz/10 min) & $58 \pm 11^{\mathrm{b}}$ & $97.27^{\mathrm{c}}$ \\
HTS (121 $\mathrm{C} / 15 \mathrm{~min})$ & $18 \pm 3^{\mathrm{c}}$ & $99.15^{\mathrm{a}}$ \\
\hline CP: Control group; PS: pasteurization; MS: microwave \\
sterilization; US: ultrasonic sterilization; HTS: high temperature \\
sterilization. Different superscript letters in the same column \\
indicate significant difference $(P<0.05)$.
\end{tabular}


(A)

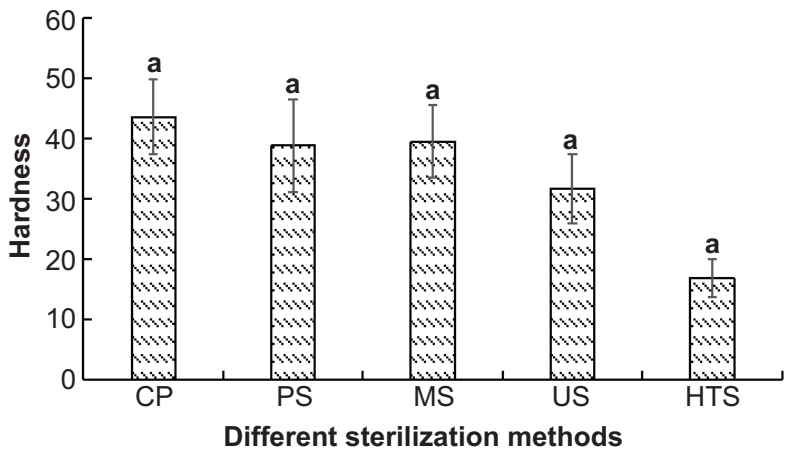

(B)

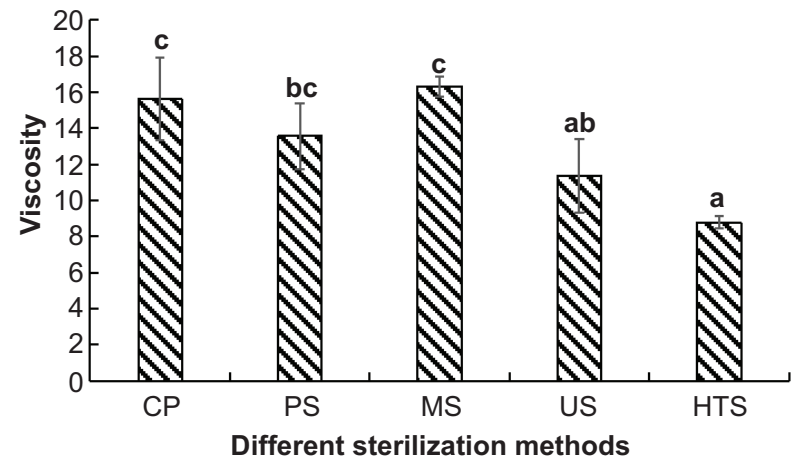

Figure 1. Effect of different sterilization methods on hardness (A) and viscosity (B) of FCMS; control group (CP); pasteurization (PS); microwave sterilization (MS); ultrasonic sterilization (US); high temperature sterilization (HTS). Different superscript letters indicate significant difference $(P<0.05)$.

change in hardness and viscosity of FCMS after PS and MS. After US treatment, there was a decrease in the viscosity of FCMS, but there was no significant change in the hardness.

Texture properties of hardness and viscosity are important indicators for evaluating a complex sauce, as they directly affect the consistency of the sauce. In this study, we found that US reduced the viscosity of FCMS, whereas HTS significantly reduced both the hardness and viscosity of FCMS. PS- and MS-treated FCMS showed no significant differences in terms of the hardness and viscosity, when compared with CP. The decrease of hardness and viscosity of FCMS probably reduces the overall consistency of FCMS. According to the GB 10612-2011 (Standards Press of China, 2011), the consistency of the complex sauce should be moderate. Therefore, in order to maintain the original consistency of FCMS, it is more appropriate to choose PS and MS to sterilize the FCMS.

\section{Color analysis}

The influence of four different sterilization methods on the color of FCMS is shown in Table 2. As can be seen, the $L^{*}, a^{*}$, and $b^{*}$ values of CP-FCMS were $23.20 \pm 0.31$, $5.14 \pm 0.45$, and $7.57 \pm 0.51$, respectively. Compared with the $\mathrm{CP}$, there was no significant difference in the $\mathrm{L}^{*}$ and $\mathrm{a}^{*}$ values of the FCMS when treated with PS and US, while the $L^{*}$ and $a^{*}$ values of the FCMS treated with MS and HTS were significantly reduced, especially for the HTStreated FCMS. The $b^{*}$ value of FCMS for all four sterilization methods showed a downward trend, with the most significant decline in the HTS group.

Color is one of the most important parameters used to evaluate the quality of sauce products. The color of sauce strongly affects consumers' purchasing preferences (Gao et al., 2015). In this study, we used the L*, $a^{*}$, and $b^{*}$ color scale to describe the color of the FCMS. The $L^{*}, a^{*}$, and $b^{*}$ values represent the degree of brightness, green-red, and blue-yellow, respectively, for different sterilization methods (Li et al., 2016). The decrease in $L^{*}$ values of FCMS in MS and HTS groups indicated that MS and HTS treatment would darken FCMS. L* values of FCMS in PS and US groups did not decrease significantly, which indicated that PS and US treatments could maintain the original brightness of FCMS. MS and HTS treatments reduced the $\mathrm{a}^{*}$ value of FCMS, indicating that these two sterilization methods reduced the redness of FCMS. In addition, all four sterilization methods reduced the $b^{*}$ value of FCMS, indicating that these four sterilization methods would reduce the yellowness of FCMS. The maximum decrease in b* value was observed in the HTS group, indicating that HTS has

Table 2. Effect of different sterilization methods on the color of FCMS.

\begin{tabular}{lrrrrr} 
& CP & PS & MS & US & HTS \\
\hline$L^{*}$ & $23.20 \pm 0.31^{\mathrm{a}}$ & $23.12 \pm 0.43^{\mathrm{a}}$ & $21.62 \pm 0.14^{\mathrm{b}}$ & $23.31 \pm 0.02^{\mathrm{a}}$ & $20.08 \pm 0.04^{\mathrm{c}}$ \\
$\mathrm{a}^{*}$ & $5.14 \pm 0.45^{\mathrm{a}}$ & $3.91 \pm 0.44^{\mathrm{ab}}$ & $3.23 \pm 0.69^{\mathrm{b}}$ & $4.60 \pm 0.82^{\mathrm{ab}}$ & $1.84 \pm 0.68^{\mathrm{c}}$ \\
$\mathrm{b}^{*}$ & $7.57 \pm 0.51^{\mathrm{a}}$ & $5.78 \pm 0.03^{\mathrm{c}}$ & $5.49 \pm 0.28^{\mathrm{c}}$ & $6.80 \pm 0.61^{\mathrm{b}}$ & $3.62 \pm 0.32^{\mathrm{d}}$ \\
$\Delta \mathrm{E}$ & & $2.22 \pm 0.24^{\mathrm{c}}$ & $3.29 \pm 0.24^{\mathrm{b}}$ & $1.25 \pm 0.16^{\mathrm{d}}$ & $6.05 \pm 0.31^{\mathrm{a}}$ \\
\hline
\end{tabular}

CP: Control group; PS: pasteurization; MS: microwave sterilization; US: ultrasonic sterilization; HTS: high temperature sterilization. Different superscript letters in the same row indicate significant difference $(P<0.05)$. 
the most significant effect on the yellowness of FCMS. $\Delta E$ represents the degree of deviation between the color of the FCMS treated with the four sterilization treatment groups and that of the untreated group. Among these four groups, the smallest $\Delta E$ was observed in the US group, followed by PS, MS, and HTS groups, respectively, which indicated that the color of FCMS in the US and PS groups is similar to that of untreated FCMS. In summary, among the four sterilization methods, US and PS treatments can maintain the original color of FCMS most effectively.

\section{Volatile compounds analysis}

A total of 63 volatile compounds were identified in five groups of FCMS. They were classified into 11 classes by their general properties and chemical structures, including 8 alcohols, 7 esters, 13 aldehydes, 3 pyrazines, 5 ketones, 1 furan, 3 acids, 10 hydrocarbons, 5 aromatics, 6 olefins, and 2 phenols, as shown in Table 3. Among the 63 volatile compounds, 35 were found in the CP group, 29 in the PS group, 38 in the MS group, 24 in the US group, and 29 in the HTS group. Figure 2 shows the composition of volatile components in unsterilized FCMS and FCMS treated with four different sterilization methods. As seen in the figure, FCMS treated with four sterilization methods had similar volatile components to the FCMS without sterilization, with alcohols, esters, aldehydes, and ketones forming the majority of the volatile components. In additionally, the volatile components of FCMS processed by HTS and MS also generated a large amount of acetic acid. Acetic acid is known to negatively affect flavors in fermented soybean products such as cheonggukjang and natto, leading to a decline in consumer acceptance (Lee et al., 2018). Therefore, HTS and MS may adversely affect the flavor quality of FCMS.

Analysis of the relative content of various main volatile components revealed an increase in the total amount of aldehydes for all the four sterilization methods, especially the PS and HTS. Aldehydes are generally produced by the degradation of lipid oxidative and amino acid Strecker reaction (Zhuang et al., 2016). Due to their high content and low odor thresholds in crab meat, aldehydes are considered to be the dominant volatile components of crab meat flavor (Yuan et al., 2020). Benzaldehyde and phenylacetaldehyde are the main aldehyde compounds in FCMS. Benzaldehyde is commonly found in crab meat of Chinese mitten crab, with a pleasant almond and caramel flavor (Ge et al., 2019). Phenylacetaldehyde is one of the primary aroma compounds in soybean paste, which can provides a fruity aroma (Xu et al., 2018) to the paste. Increasing the content of benzaldehyde and phenylacetaldehyde will help the formation of good flavors in FCMS. In terms of aldehyde content, all four sterilization treatments contributed to the formation of good flavors of FCMS, especially PS and HTS.

Ester compounds are the primary components of the aroma in soybean paste. They can also enhance the smell of other flavor compounds, and can also reduce the salty taste of the sauce (Chen et al., 2016). A total of seven ester compounds were detected in the five groups of FCMS in this study. Among them, ethyl acetate, ethyl benzoate, ethyl octoate, and ethyl dodecanoate were detected in the five groups of FCMS. The ethyl acetate content was the highest, and it was the major aldehyde compound found in FCMS. Ethyl benzoate is present in the soybean paste, which provides grape aroma and strong smell, and plays an important role in the aroma of soybean paste (Peng and Wang, 2019). Treatment with PS and US brought about an increase in the levels of ethyl acetate and ethyl benzoate in FCMS. In addition, we found that treatment with MS and HTS reduces the total number of esters, while PS treatment maintains the total number of esters; and, US treatment increases the total number of esters in FCMS. In terms of esters, PS and US efficiently maintain the original soybean flavor of FCMS.

Alcohol contributes significantly to the flavor formation in soybean paste, and can present a pleasant sweetness (Xu et al., 2018). In this study, we found that the total alcohol content of FCMS increased after treatment with PS, MS, and HTS, notably in PS and MS treatments, where total alcohol levels reached 28.95 and $29.17 \%$, respectively. Among the five groups of FCMS, ethanol and phenethyl alcohol were the most commonly found alcoholic compounds. Phenyl alcohol is a common flavoring agent that imparts a scent of roses to food (Xu and Chang, 2008). After PS and MS treatments, the content of phenethyl alcohol in FCMS increased, which contributed to the formation of the overall flavor of FCMS. Therefore, in terms of alcohol compounds, PS and MS may make the flavor of FCMS richer.

Ketones are mainly produced by thermal oxidation of PUFA, amino acid degradation, or Maillard reaction (Zhuang et al., 2016). Ketones in crustacean aquatic products generally have floral and fruity aromas, but ketones with fewer carbon atoms have a higher threshold and have little effect on the overall flavor formation (Yu et al., 2007). In this study, we detected a total of six ketone compounds from five groups of FCMS, of which 1-(1H-pyrrole-2-yl)-ethanone has the highest content and is the main ketone in FCMS. Moreover, the total amount of ketones increased after MS and HTS treatments. The reason for this phenomenon was probably related to the formation conditions of ketone compounds, and higher sterilization temperature might lead to the increase in total ketone content of MS and HTS treatment groups (Apichartsrangkoon et al., 2009). 
Yajun Zhu et al.

Table 3. Volatile compounds of FCMS treated with different sterilization methods.

\begin{tabular}{|c|c|c|c|c|c|c|}
\hline \multirow[t]{2}{*}{ Category } & \multirow[t]{2}{*}{ Volatile compounds } & \multicolumn{5}{|c|}{ Relative percentage (\%) } \\
\hline & & $\mathrm{CP}$ & PS & MS & US & HTS \\
\hline \multirow[t]{8}{*}{ Alcohols } & Ethanol & $9.36 \pm 0.63^{b}$ & $16.84 \pm 0.99^{a}$ & $14.66 \pm 0.19^{a}$ & $0.71 \pm 0.07^{c}$ & $14.05 \pm 2.44^{\mathrm{a}}$ \\
\hline & 2-furan methanol & $2.17 \pm 0.84^{\mathrm{a}}$ & $2.11 \pm 0.92^{\mathrm{a}}$ & $3.42 \pm 0.58^{\mathrm{a}}$ & $2.86 \pm 0.35^{\mathrm{a}}$ & $2.55 \pm 1.03^{\mathrm{a}}$ \\
\hline & 1-octen-3-ol & - & $0.11 \pm 0.03$ & - & - & - \\
\hline & Phenylethanol & $8.33 \pm 1.06^{a}$ & $9.01 \pm 0.29^{a}$ & $8.59 \pm 1.04^{\mathrm{a}}$ & $9.64 \pm 1.84^{\mathrm{a}}$ & $4.69 \pm 1.18^{b}$ \\
\hline & 2-methylene cyclopentanol & - & $0.50 \pm 0.06^{\mathrm{a}}$ & - & - & $0.22 \pm 0.09^{b}$ \\
\hline & $\begin{array}{l}\alpha, \alpha, 4 \text {-trimethyl-3-cyclohexene-1- } \\
\text { methanol }\end{array}$ & - & $0.38 \pm 0.12^{b}$ & - & $0.45 \pm 0.03^{\mathrm{a}}$ & $0.47 \pm 0.05^{\mathrm{a}}$ \\
\hline & 2-(dodecyloxy)-ethanol & - & - & $1.12 \pm 0.15$ & - & - \\
\hline & 2-tetradecanyl alcohol & - & - & $1.38 \pm 0.23$ & - & - \\
\hline Subtotal & & 19.86 & 28.95 & 29.17 & 13.66 & 21.98 \\
\hline \multirow[t]{7}{*}{ Esters } & Ethyl butyrate & $1.01 \pm 0.32^{b}$ & $0.73 \pm 0.27^{b}$ & - & $1.85 \pm 0.18^{\mathrm{a}}$ & - \\
\hline & Ethyl hexanoate & $30.95 \pm 8.07^{a b}$ & $30.98 \pm 8.89^{\mathrm{ab}}$ & $15.57 \pm 2.59^{c}$ & $43.02 \pm 2.06^{a}$ & $26.91 \pm 2.50^{b c}$ \\
\hline & Ethyl benzoate & $0.43 \pm 0.24^{a}$ & $0.56 \pm 0.05^{a}$ & $0.34 \pm 0.14^{a}$ & $0.52 \pm 0.10^{\mathrm{a}}$ & $0.45 \pm 0.10^{a}$ \\
\hline & Ethyl octoate & $0.36 \pm 0.12^{\mathrm{a}}$ & $0.37 \pm 0.05^{\mathrm{a}}$ & $0.30 \pm 0.07^{a}$ & $0.45 \pm 0.10^{\mathrm{a}}$ & $0.36 \pm 0.03^{a}$ \\
\hline & Ethyl eicosanate & $0.23 \pm 0.08^{a}$ & $0.25 \pm 0.06^{\mathrm{a}}$ & $0.32 \pm 0.14^{\mathrm{a}}$ & $0.18 \pm 0.07^{a}$ & $0.19 \pm 0.07^{a}$ \\
\hline & 4-tert-butylcyclohexyl acetate & - & - & $1.14 \pm 0.24$ & - & - \\
\hline & Dodecyl acetate & - & - & $0.81 \pm 0.25$ & - & - \\
\hline Subtotal & & 32.98 & 32.89 & 18.48 & 46.02 & 27.90 \\
\hline \multirow[t]{13}{*}{ Aldehydes } & 3-(methylthio)-propanal & $0.60 \pm 0.05^{a}$ & $0.75 \pm 0.24^{a}$ & $0.81 \pm 0.11^{\mathrm{a}}$ & $0.64 \pm 0.18^{a}$ & $0.84 \pm 0.19^{a}$ \\
\hline & 2-heptanal & $0.39 \pm 0.09^{c}$ & $1.81 \pm 0.12^{b}$ & $1.88 \pm 0.09^{b}$ & $6.42 \pm 0.40^{\mathrm{a}}$ & $1.48 \pm 0.32^{b}$ \\
\hline & Benzaldehyde & $1.30 \pm 0.18^{c}$ & $3.96 \pm 0.57^{\mathrm{a}}$ & $3.47 \pm 0.64^{b}$ & - & $4.19 \pm 0.37^{a}$ \\
\hline & 2,4-heptadienal & $2.64 \pm 1.31^{\mathrm{ab}}$ & $2.76 \pm 0.22^{\mathrm{ab}}$ & $1.21 \pm 0.19^{b}$ & $2.69 \pm 0.52^{\mathrm{ab}}$ & $4.01 \pm 0.41^{\mathrm{a}}$ \\
\hline & Phenylacetaldehyde & $4.24 \pm 0.18^{c}$ & $5.66 \pm 0.39^{\mathrm{abc}}$ & $7.52 \pm 0.86^{\mathrm{a}}$ & $5.19 \pm 1.10^{b c}$ & $7.01 \pm 1.05^{\mathrm{ab}}$ \\
\hline & 2-octenal & $1.15 \pm 0.15^{\mathrm{a}}$ & $1.33 \pm 0.25^{\mathrm{a}}$ & - & $1.59 \pm 0.35^{\mathrm{a}}$ & $1.37 \pm 0.35^{\mathrm{a}}$ \\
\hline & 3,7-dimethyl-2,6-octadienal & $1.25 \pm 0.33^{b}$ & $2.87 \pm 0.13^{\mathrm{a}}$ & $1.06 \pm 0.51^{b}$ & $1.13 \pm 0.13^{b}$ & $1.16 \pm 0.35^{b}$ \\
\hline & 2-decenal & $3.06 \pm 0.11^{b}$ & $3.95 \pm 0.92^{\mathrm{ab}}$ & $5.16 \pm 0.24^{\mathrm{a}}$ & $3.39 \pm 0.57^{b}$ & $4.26 \pm 0.47^{\mathrm{ab}}$ \\
\hline & 2,4-decadienal & $1.27 \pm 0.02^{b}$ & $1.38 \pm 0.07^{a b}$ & $0.46 \pm 0.06^{c}$ & $0.44 \pm 0.09 c$ & $1.44 \pm 0.08^{a}$ \\
\hline & 2-undecenal & $0.21 \pm 0.11$ & - & - & - & - \\
\hline & $\begin{array}{l}\text { 4-methoxybenzene (methyl) } \\
\text { aldehyde }\end{array}$ & $0.40 \pm 0.14$ & - & - & - & - \\
\hline & Sugar aldehyde & - & - & - & - & $2.66 \pm 0.54$ \\
\hline & Nonanal & - & - & - & - & - \\
\hline Subtotal & & 19.85 & 24.47 & 21.33 & 21.74 & 28.42 \\
\hline \multirow[t]{3}{*}{ Pyrazines } & 2,5-dimethyl-pyrazine & $0.95 \pm 0.23^{b}$ & $0.97 \pm 0.16^{b}$ & $2.72 \pm 0.39^{a}$ & $1.08 \pm 0.24^{b}$ & - \\
\hline & 2-ethyl-3,5-dimethyl-pyrazine & $0.36 \pm 0.08$ & - & - & - & - \\
\hline & 2-vinyl-6-methyl-pyrazine & - & - & $2.36 \pm 0.16$ & - & - \\
\hline Subtotal & & 1.31 & 0.97 & 5.08 & 1.08 & - \\
\hline \multirow[t]{5}{*}{ Ketones } & 1-octen-3-one & - & $0.41 \pm 0.18^{\mathrm{a}}$ & - & - & $0.49 \pm 0.06^{a}$ \\
\hline & 1- (1H-pyrrole-2-yl) -ethanone & $2.74 \pm 0.38^{b}$ & $3.40 \pm 0.69^{a b}$ & $4.84 \pm 0.48^{\mathrm{a}}$ & $3.76 \pm 1.18^{\mathrm{ab}}$ & $4.20 \pm 0.71^{\mathrm{ab}}$ \\
\hline & $\begin{array}{l}\text { 1- (4-hydroxy-3,5- } \\
\text { dimethoxyphenyl)-ethanone }\end{array}$ & $0.35 \pm 0.12$ & - & - & - & - \\
\hline & $\begin{array}{l}\text { 1- (2-hydroxy-4,6-dimethoxyphenyl)- } \\
\text { ethanone }\end{array}$ & $0.16 \pm 0.05$ & - & - & - & - \\
\hline & $\begin{array}{l}\text { 2,3-dihydro-3,5-dihydroxy-6-methyl- } \\
\text { 4H-pyran-4-one }\end{array}$ & - & - & $0.87 \pm 0.30^{b}$ & - & $1.55 \pm 0.38^{\mathrm{a}}$ \\
\hline Subtotal & & 3.25 & 3.81 & 5.71 & 3.76 & 6.24 \\
\hline Furans & 2-pentyl-furan & $0.21 \pm 0.12^{b}$ & $0.44 \pm 0.17^{a b}$ & $0.47 \pm 0.07^{\mathrm{a}}$ & $0.33 \pm 0.07^{a b}$ & $0.38 \pm 0.06^{\mathrm{ab}}$ \\
\hline Subtotal & & 0.21 & 0.44 & 0.47 & 0.33 & $\begin{array}{l}0.38 \\
\text { (continues) }\end{array}$ \\
\hline
\end{tabular}


Table 3. Continued

\begin{tabular}{|c|c|c|c|c|c|c|}
\hline \multirow[t]{2}{*}{ Category } & \multirow[t]{2}{*}{ Volatile compounds } & \multicolumn{5}{|c|}{ Relative percentage (\%) } \\
\hline & & $\mathrm{CP}$ & PS & MS & US & HTS \\
\hline \multirow[t]{3}{*}{ Acids } & Sorbic acid & $1.20 \pm 0.45^{a}$ & $1.19 \pm 0.18^{a}$ & $0.82 \pm 0.23^{a}$ & $0.84 \pm 0.16^{a}$ & $0.21 \pm 0.06^{b}$ \\
\hline & Salicyl <0-hydroxybenzyl> acid & - & - & $0.24 \pm 0.17$ & - & - \\
\hline & Acetic acid & - & - & $6.24 \pm 0.41^{b}$ & - & $8.20 \pm 0.71^{a}$ \\
\hline Subtotal & & 1.20 & 1.19 & 8.35 & 0.84 & 0.41 \\
\hline \multirow[t]{10}{*}{ Hydrocarbons } & 6,9-dimethyl-tetradecane & - & $0.17 \pm 0.15$ & - & - & - \\
\hline & Octane & - & - & - & - & - \\
\hline & $\begin{array}{l}\text { 4-methylene-1-(1-methylethyl)- } \\
\text { bicyclo [3.1.0] hexane }\end{array}$ & $1.24 \pm 0.59^{\mathrm{a}}$ & - & - & $1.61 \pm 0.40^{\mathrm{a}}$ & - \\
\hline & 2-methyl-tridecane & $0.15 \pm 0.04$ & - & - & - & - \\
\hline & Tetradecane & - & - & $0.46 \pm 0.15$ & - & - \\
\hline & Undecane & - & - & $0.10 \pm 0.05$ & - & - \\
\hline & Nonyl-cyclopropane & - & - & $0.44 \pm 0.07$ & - & - \\
\hline & Cyclotetradecane & - & - & $0.35 \pm 0.14$ & - & - \\
\hline & Cyclodecane & - & - & $0.58 \pm 0.14$ & - & - \\
\hline & Cyclododecane & - & - & $0.40 \pm 0.20$ & - & - \\
\hline Subtotal & & 1.39 & 0.17 & 2.33 & 1.61 & - \\
\hline \multirow[t]{5}{*}{ Aromatics } & Phenylpropionitrile & $0.81 \pm 0.17^{a}$ & $1.00 \pm 0.36^{a}$ & $0.76 \pm 0.14^{a}$ & $1.07 \pm 0.20^{\mathrm{a}}$ & $1.13 \pm 0.33^{a}$ \\
\hline & $\begin{array}{l}\text { 1-methoxy-4- (1-propenyl) } \\
\text {-benzene }\end{array}$ & $4.81 \pm 1.10^{\mathrm{a}}$ & $4.97 \pm 1.24^{\mathrm{a}}$ & $0.98 \pm 0.16^{b}$ & $2.53 \pm 0.41^{b}$ & $1.77 \pm 0.28^{b}$ \\
\hline & 1-butylheptyl-benzene & - & - & $0.39 \pm 0.09$ & - & - \\
\hline & 1-pentylheptyl-benzene & - & - & $0.21 \pm 0.09$ & - & - \\
\hline & 1-butyloctyl-benzene & - & - & $0.15 \pm 0.08$ & - & - \\
\hline Subtotal & & 5.62 & 5.97 & 2.49 & 3.60 & 2.90 \\
\hline \multirow[t]{6}{*}{ Olefins } & $\begin{array}{l}\text { 4-methyl-1- (1-methylethyl) -bicyclo } \\
\text { [3.1.0] hex-2-ene }\end{array}$ & $1.24 \pm 0.29^{a}$ & $1.24 \pm 0.16^{a}$ & - & - & - \\
\hline & $\begin{array}{l}\text { 7,11-dimethyl-3-methylene-1,6,10- } \\
\text { dodecanetriene }\end{array}$ & $0.15 \pm 0.04$ & - & - & - & - \\
\hline & $\beta$-phellandrene & $1.39 \pm 0.08^{a}$ & - & - & - & $1.03 \pm 0.15^{\mathrm{a}}$ \\
\hline & Trans- $\alpha$-bergamotene & $0.39 \pm 0.13$ & - & - & - & - \\
\hline & 1-decene & - & - & $2.73 \pm 0.19$ & - & - \\
\hline & 2-tetradecene & - & - & $0.63 \pm 0.14$ & - & - \\
\hline Subtotal & & 3.17 & 1.24 & 3.36 & - & 1.03 \\
\hline \multirow[t]{2}{*}{ Phenols } & Eugenol & $0.32 \pm 0.08$ & - & - & - & - \\
\hline & 2-methoxy-4-vinylphenol & - & - & - & - & $0.36 \pm 0.18$ \\
\hline Subtotal & & 0.32 & - & - & - & 0.36 \\
\hline
\end{tabular}

CP: control group; PS: pasteurization; MS: microwave sterilization; US: ultrasonic sterilization; HTS: high temperature sterilization. Different superscript letters in the same row indicate significant differences $(P<0.05)$.

Overall, compared with other sterilization methods, PS efficiently maintains the original flavor of FCMS, and even improves its flavor to a certain extent.

\section{Sensory analysis}

The four groups of FCMS were, respectively, subjected to PS, MS, US, and HTS. Sensory evaluation was performed on the products according to the preference. Higher scores indicate higher consumer satisfaction with FCMS. The evaluation results are shown in Figure 3.

As seen in Figure 3, compared with the untreated group, we found that FCMS treated with PS and US maintained its original state in terms of umami, sweetness, saltiness, ester, and posture but showed a decrease in color, sauce, and taste coordination. However, the sensory evaluation 


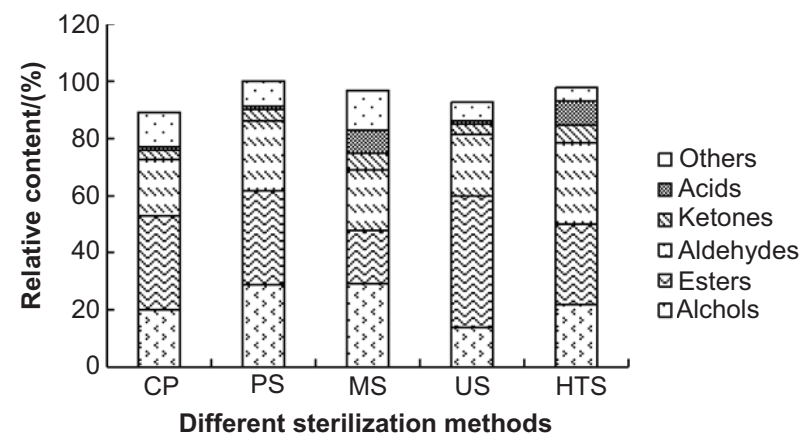

Figure 2. Composition of volatile components in FCMS under different sterilization treatments; control group (CP), pasteurization (PS), microwave sterilization (MS), ultrasonic sterilization (US), high temperature sterilization (HTS).

of FCMS treated by MS and HTS decreased in all aspects. Therefore, in terms of sensory evaluation, FCMS after PS and US may be more popular with consumers.

\section{Conclusions}

On the basis of the results of the present study, we conclude that FCMS processed by the four sterilization methods meets the requirements of commercial sterilization, but these methods influence the sensory quality and flavor of the FCMS. In terms of sensory indicators, compared with the untreated group, PS and MS had no significant effect on the texture of FCMS, but US and HTS reduced the hardness and viscosity of FCMS. MS and HTS significantly reduced the $\mathrm{L}^{*}, \mathrm{a}^{*}$, and $\mathrm{b}^{*}$ values of FCMS, while PS and US could maintain the original brightness and red value of FCMS well. MS and HTS greatly reduced the sensory score of FCMS, while PS and US maintained the original sensory score of FCMS. We observed that PS and US efficiently maintained the original sensory quality of FCMS. In terms of volatile flavor, MS and HTS reduced the ester content in FCMS, US reduced the alcohol content in FCMS, while PS not only maintained the original ester content of the FCMS but also increased the content of alcohol, aldehydes, and ketones. Overall, according to the results of volatile flavor and sensory analysis, PS can better maintain the original sensory quality of FCMS and improve the flavor of FCMS compared with other sterilization methods. The results of this study can provide a reference for finding an optimum sterilization method for FCMS.

\section{Acknowledgments}

This research was financially supported by the earmarked fund for Anhui Provincial Modern Agro-industry Technology Research System (AHCYJSTX-08) and China Agriculture Research System of MOF and MARA.

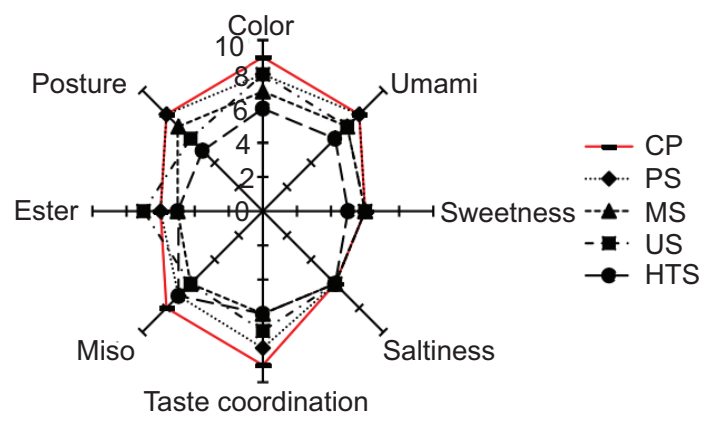

Figure 3. Sensory evaluation of FCMS before and after four sterilization treatments; control group (CP), pasteurization (PS), microwave sterilization (MS), ultrasonic sterilization (US), high temperature sterilization (HTS).

\section{Conflict of Interest}

The authors declare no competing financial interest of this research.

\section{References}

Apichartsrangkoon, A., Wongfhun, P. and Gordon, M.H., 2009. Flavor characterization of sugar-added pennywort (Centella asiatica L.) juices treated with ultra-high pressure and thermal processes. Journal of Food Science 74(9): C643-C646. https:// doi.org/10.1111/j.1750-3841.2009.01358.x

Bu, Y.F., Zhao, L.Z., Yin, L.B., Zhou, X.H., Jiang, Q.H., Li, W.Q., et al. 2014. Microbial detection and safety control during production of stewed dried tofu. Food Science 35(5): 107-110. (in Chinese with English abstract). https://doi.org/10.7506/ spkx1002-6630-201405021

Chen, D.W. and Zhang, M., 2007. Non-volatile taste active compounds in the meat of Chinese mitten crab (Eriocheir sinensis). Food Chemistry 104(3): 1200-1205. https://doi.org/10.1016/j. foodchem.2007.01.042

Chen, J.H., Chen, L., Cui, C. and Xu, M., 2016. Effect of steaming time on flavor characteristics of soybean paste. China Condiment 41(11): 1-4, 9. (in Chinese with English abstract). https://doi.org/10.3969/j.issn.1000-9973.2016.11.001

Chen, Y., Chen, G.Y., Wei, R., Zhang, Y.F., Li, S.H. and Chen, Y., 2019. Quality characteristics of fresh wet noodles treated with nonthermal plasma sterilization. Food Chemistry 297(11): 1-7. https://doi.org/10.1016/j.foodchem.2019.05.174

Cheng, Y.X., Wu, X.G., Yang, X.Z. and Hines, A.H., 2008. Current trends in hatchery techniques and stock enhancement for Chinese mitten crab, Eriocheir japonica sinensis. Reviews in Fisheries Science 16: 377-384. https://doi. org/10.1080/10641260701681698

Dong, W.J., Hu, R.S., Long, Y.Z., Li, H.H., Zhang, Y.J., Zhu, K.X., et al. 2019. Comparative evaluation of the volatile profiles and taste properties of roasted coffee beans as affected by drying method and detected by electronic nose, electronic tongue, and 
HS-SPME-GC-MS. Food Chemistry 272: 723-731. https://doi. org/10.1016/j.foodchem.2018.08.068

Gao, X.L., Cui, C., Zhao, H.F., Zhao, M.M., Yang, L. and Ren, J.Y., 2010. Changes in volatile aroma compounds of traditional Chinese-type soy sauce during moromi fermentation and heat treatment. Food Science and Biotechnology 19(4): 889-898. https://doi.org/10.1007/s10068-010-0126-7

Gao, Y., Zhang, M., Wang, Y., Mujumdar, A.S. and Chen, W., 2015. Textural and sensory properties of herring (Clupea harengus) cubes in Chinese-type paste as affected by prefrying methods. Journal of Aquatic Food Product Technology 24(2): 179-190. https://doi.org/10.1080/10498850.2013.767297

Ge, M.T., Li, X.C., Lin, L., Jiang, S.T. and Lu, J.F., 2019. Comparison of volatile compounds in crab meat from four regions in China. China Condiment 44(04): 16-22. (in Chinese with English abstract). https://doi.org/10.3969/j.issn.1000-9973.2019.04.004

Gu, S.Q., Wang, X.C., Tao, N.P. and Wu, N., 2013. Characterization of volatile compounds in different edible parts of steamed Chinese mitten crab (Eriocheir sinensis). Food Research International 54(1): 81-92. https://doi.org/10.1016/j.foodres.2013.05.018

Kargiotou, C., Katsanidis, E., Rhoades, J., Kontominas, M. and Koutsoumanis, K., 2011. Effificacies of soy sauce and wine base marinades for controlling spoilage of raw beef. Food Microbiology 28: 158-163. https://doi.org/10.1016/j. fm.2010.09.013

Lee, E.J., Hyun, J., Choi, Y.H., Hurh, B.S., Choi, S.H. and Lee, I., 2018. Development of safe and flavor-rich Doenjang (Korean fermented soybean paste) using autochthonous mixed starters at the pilot plant scale. Journal of Food Science 83(6): 17231732. https://doi.org/10.1111/1750-3841.14166

Li, M., Zhu, K.X., Sun, Q.J., Amza, T., Guo, X.N. and Zhou, H.M., 2016. Quality characteristics, structural changes, and storage stability of semi-dried noodles induced by moderate dehydration: Understanding the quality changes in semi-dried noodles. Food Chemistry 194: 797-804. https://doi.org/10.1016/j. foodchem.2015.08.079

Peng, C. and Wang, Y.Q., 2019. Study on the effect of heat-treated wheat flour on the flavor of soybean paste. China Condiment 44(03): 136-140. (in Chinese with English abstract). https://doi. org/10.3969/j.issn.1000-9973.2019.03.030

Standards Press of China, 2009. Chinese Standard GB 24399-2009. Method for determination of sensory score in foods. Beijing, China: Standards Press of China.

Standards Press of China, 2010. Chinese Standard GB 4789.3-2010. Method for determination of coliform enumeration in foods. Beijing: Standards Press of China.

Standards Press of China, 2011. Chinese Standard GB 10612-2011. Domestic trade industry standard of soy complex sauce. Beijing: Standards Press of China.

Standards Press of China, 2016. Chinese Standard GB 4789.22016. Method for determination of total viable counts in foods. Beijing: Standards Press of China.

Wanakhachornkrai, P. and Lertsiri, S., 2003. Comparison of determination method for volatile compounds in Thai soy sauce.
Food Chemistry 83(4): 619-629. https://doi.org/10.1016/ S0308-8146(03)00256-5

Wang, Q.J., Wu, X.G., Long, X.W., Zhu, W.L., Ma, T.L. and Cheng, Y.X., 2018. Nutritional quality of different grades of adult male Chinese mitten crab, Eriocheir sinensis. Journal of Food Science and Technology 55(3): 944-955. https://doi. org/10.1007/s13197-017-3002-0

Wang, S., He, Y., Wang, Y.Y., Tao, N.P., Wu, X.G., Wang, X.C., et al. 2016. Comparison of flavour qualities of three sourced Eriocheir sinensis. Food Chemistry 200: 24-31. https://doi.org/10.1016/j. foodchem.2015.12.093

Wu, H.R., Ge, M.T., Chen, H.F., Jiang, S.T., Lin, L. and Lu, J.F., 2020. Comparison between the nutritional qualities of wild-caught and rice-field male Chinese mitten crabs (Eriocheir sinensis). LWT-Food Science and Technology 117: 108663. https://doi. org/10.1016/j.lwt.2019.108663

Wu, H.R., Ge, M.T., Zhou, X.H., Jiang, S.T. and Lu, J.F., 2019a. Nutritional qualities of normal and precocious adult male Chinese mitten crabs (Eriocheir sinensis). Aquaculture Research 50(8): 2267-2275. https://doi.org/10.1111/are.14107

Wu, H.R., Lin, L., Chen, H.F., Jiang, S.T. and Lu, J.F., 2019b. The quality evaluation and analysis of the nutritional components in mitten crab scrap in segmentation processing. Meat Industry 06: 31-36, 57. (in Chinese with English abstract). https://doi.org/ CNKI:SUN:RLGY.0.2019-06-007

Xu, B. and Chang, S.K.C., 2008. Antioxidant capacity of seed coat, dehulled bean, and whole black soybeans in relation to their distributions of total phenolics, phenolic acids, anthocyanins, and isoflavones. Journal of Agricultural and Food Chemistry 56(18): 8365-8373. https://doi.org/10.1021/jf801196d

Xu, D.D., Wang, W.P., Wang, P., Zhang, X., Zhang, J., Ding, J., et al. 2018. Comparison and analysis of quality and volatile compounds of black bean paste and soybean paste. China Brewing 37(11): 30-35. (in Chinese with English abstract). https://doi. org/10.11882/j.issn.0254-5071.2018.11.007

Ye, T., Chen, Z.N., Ye, Q.W., Liu, H.Q., Wang, Y. and Lu, J.F., 2020. Effect of different sterilization methods on isoflavone profiles and quality characteristics of ready-to-eat dried soybean curd (Tofu). Food Science 41(7): 124-130. (in Chinese with English abstract). https://doi.org/10.7506/spkx1002-6630-20190304-040

Yu, X., Voort, F.R.V.D. and Sedman, J., 2007. Determination of peroxide value of edible oils by ftir spectroscopy with the use of the spectral reconstitution technique. Talanta 74(2): 241-246. https://doi.org/10.1016/j.talanta.2007.06.004

Yuan, Y., Wang, X.X., Jin, M., Jiao, L.F., Sun, P., Betancor, M.B., et al. 2020. Modification of nutritional values and flavor qualities of muscle of swimming crab (Portunus trituberculatus): application of a dietary lipid nutrition strategy. Food Chemistry 308: 125607. https://doi.org/10.1016/j.foodchem.2019.125607

Zhuang, K.J., Wu, N., Wang, X.C., Wu, X.G., Wang, S., Long, X.W., et al. 2016. Effects of 3 feeding modes on the volatile and nonvolatile compounds in the edible tissues of female Chinese mitten crab (Eriocheir sinensis). Journal of Food Science 81(4): S968-S981. https://doi.org/10.1111/1750-3841.13229 